\title{
"Chile para todas las razas": Respuestas de la prensa antifascista al antisemitismo del Partido Nacional Fascista de Chile (1938-1940) ${ }^{1}$
}

\author{
"Chile for all races": Responses of the Anti-Fascist Press to the Chilean Partido Nacional \\ Fascista's Antisemitism (1938-1940) \\ Gustavo Guzmán \\ gu.guzman@gmail.com \\ The Southern Cross School Chile
}

\section{Resumen}

Durante los años treinta del siglo pasado, se produjo en Chile una proliferación de agrupaciones nacionalistas de derecha contrarias al liberalismo, la democracia y el comunismo. En algunos casos, tales agrupaciones adoptaron también el fascismo y el antisemitismo provenientes de Europa, desarrollando campañas antijudías inéditas en la Historia de Chile. El presente artículo indaga en las respuestas de la prensa antifascista chilena al antisemitismo del Partido Nacional Fascista (PNF), principal agrupación antisemita de los años treinta, destacando su colaboración con el semanario sionista Mundo Judio.

Palabras clave: Antisemitismo en Chile - Prensa antifascista de Chile - Partido Nacional Fascista de Chile

\footnotetext{
${ }^{1}$ El presente artículo sintetiza el capítulo 9 de "La patria sin judíos: Antisemitismo nacionalista en Chile, 1932-1940. Los casos del Movimiento Nacional Socialista y del Partido Nacional Fascista", tesis para acceder al grado de Magíster en Historia, mención Historia de Europa, de la Universidad de Chile.
} 


\begin{abstract}
During the thirties many right-wing nationalist groups appeared in Chile. Most of them declared to be against Liberalism, Democracy and Communism. In some cases these groups also embraced the Fascism and the Antisemitism coming from Europe, developing antiSemitic campaigns, unprecedented in the Chilean History. This article enquires in the responses of the Chilean Anti-Fascist press to the Anti-Semitism of the Partido Nacional Fascista (PNF), main anti-Semitic group of the thirties, highlighting its collaboration with the Zionist weekly paper Mundo Judio.
\end{abstract}

Key words: Anti-Semitism in Chile -Chilean Anti-Fascist Press-Chilean Partido Nacional Fascista

El sábado 24 de junio de 1939, siete meses después de la llegada del Frente Popular a La Moneda y algunas semanas antes de la declaración de guerra británica contra Alemania, el semanario La Patria, publicación oficial del Partido Nacional Fascista, tituló "La inmigración de judíos significa la ruina de Chile". Según los editores, era su deber -como "verdaderos chilenos, nacidos en Chile"- denunciar el "peligro que encierra una fuerte inmigración de elementos expulsados de otros países por indeseables y que no significan en absoluto ningún progreso al país que les sirve de hotel" así como el hecho de que "nuestra nacionalidad está amenazada por el nacionalismo de una raza intransigente que (...) quiere la destrucción de la cristiana civilización de occidente, de su moral y de todas las bases en que ella se sostiene". De esta manera, el semanario fascista expresaba su rechazo a la reciente llegada del vapor italiano Orduña a las costas chilenas, con "cerca de 1.000 judíos, que no habían sido recibidos en ningún país de América” y su solidaridad con los países que rechazaban la inmigración israelita, pues "sabido es que el judío no es un hombre de trabajo. Jamás se ha visto a un judío en el campo, detrás de un arado. Busca la vida fácil, el comercio, y el comercio usurario". Recurriendo al discurso conspirativo que lo 
caracterizaba, el semanario del PNF afirmaba que "donde uno converja la vista, verá ya las manifestaciones de la existencia del judaísmo en nuestro país. En el comercio, principalmente, los señores de Israel han mostrado su faz. En la Bolsa y en los círculos bursátiles", así como en las tradicionales galerías del centro de Santiago, donde "se han visto colocar nuevos nombres de profesionales: médicos, dentistas, abogados, todos ellos judíos" (La Patria, 24 junio 1939, p. 1).

Manifestaciones antisemitas como ésta, prácticamente inexistentes en Chile hasta los años treinta del siglo pasado, se repetirían sistemáticamente en cada una de las veintiocho ediciones de La Patria, entre junio de 1939 y marzo de 1940, dando al PNF un perfil ideológico similar al de sus pares europeos, inspirado en un novedoso y radical discurso antisemita. El presente artículo indaga en las reacciones que tales expresiones suscitaron en la prensa antifascista de la época, para lo cual ha sido dividido en tres partes: la primera da cuenta del estado de la cuestiónen el estudio del PNF; la segunda se centra en el antisemitismo de este partido, expresado principalmente a través de su semanario; y la tercera expone las principales reacciones de la prensa antifascista chilena de la época frente al antisemitismo del PNF, destacando su colaboración con el semanario sionista Mundo Judío.

\section{La bibliografía sobre el Partido Nacional Fascista de Chile}

Como sintetizamos en otros lugar (Guzmán Castro, 2014), a diferencia de la bibliografía dedicada a sus antecesores nacistas ${ }^{2}$ (Pike, 1963; Bicheno, 1972; Potashnik, 1974; Ramírez Necochea, 1978; Grugel, 1985; Sznajder, 1990, 1992; Etchepare y Stewart, 1995; Deutsch, 1996, 2005) los estudios sobre el Partido Nacional Fascista, principal agrupación fascista chilena de fines de los años treinta, son muy escasos, limitándose a los trabajos de Verónica Valdivia (1993, 1995) y Marcus Klein (2000, 2001).

\footnotetext{
${ }^{2}$ Recordemos que para diferenciarse del nazismo alemán, los miembros del Movimiento Nacional Socialista de Chile, liderado por Jorge González von Marées, se hacían llamar “nacistas”, con ce.
} 
En el primero de sus trabajos sobre los grupos nacionalistas nacidos tras el quiebre del MNS, Valdivia (1993) plantea tres ideas útiles a nuestro estudio. En primer lugar, que la llegada del Frente Popular a la Presidencia de la República, a fines de 1938, constituye un factor fundamental para comprender el surgimiento de grupos fascistas como el PNF. Según Valdivia, la derecha, en general, habría tenido importantes dificultades para asumir su derrota electoral, adoptando una postura de abierta oposición al nuevo gobierno; los grupos nacionalistas herederos del MNS, en particular, habrían desconocido "por completo" el triunfo frentista, "luchando por su destitución y la destrucción del orden democrático-liberal que había permitido su ascenso". De esta manera, el triunfo de Aguirre Cerda habría hecho que se reprodujera en Chile la polarización ideológica europea entre fascismos y democracias: la defensa del orden político existente fue encabezada por el Frente Popular, mientras que "la línea pro-totalitaria fascistoide fue adoptada por los grupos de tendencia nacionalista que habían madurado durante la década de 1930" en el seno del MNS, como el PNF (Valdivia, 1993, pp. 119-20). En segundo lugar, la semejanza ideológica del PNF respecto de sus símiles europeos, semejanza que se explicaría por los éxitos de las potencias fascistas europeasen los años previos a la Segunda Guerra Mundial, los que habrían encandilado al fascismo chileno. Sería esta ligazón ideológica con el fascismo europeo, más que acciones de espionaje o de colaboración propiamente tales, las que explicarían las permanentes acusaciones en contra del PNF de formar la "Quinta Columna" en Chile (Valdivia, 1993, pp. 127-30). Y, en tercer lugar, la marginalidad política del PNF. Según la autora, pese a todos sus esfuerzos el partido encabezado por Raúl Olivares Maturana "no dejó de ser marginal” ni logró “atraer los militantes suficientes como para convertirse realmente en un movimiento nacional". Las razones se encontrarían en la polarización ideológica de la política chilena de fines de los años treinta: la robustez de la derecha tradicional y la intransigencia ideológica del PNF habrían confinado a éste último a los márgenes de la escena política, a la extrema derecha, impidiendo que se acercara a la derecha tradicional, "único tronco que podía haberlo fortalecido" (Valdivia, 1993, pp. 130-1). 
En su segundo trabajo sobre los grupos nacionalistas de los años del Frente Popular, Valdivia (1995) destaca la importancia del contexto político internacional en el nacimiento y desarrollo de grupos como el PNF. En este sentido, cree que la crisis del capitalismo y el estallido de la Segunda Guerra Mundial habrían creado "condiciones históricas favorables al desarrollo de tendencias anti-internacionalistas y nacionalistas" a nivel mundial. No obstante, al momento de nacer el PNF, a fines de los años treinta, habían comenzado a "debilitarse las figuras de Hitler y Mussolini, al iniciarse su seguidilla de fracasos", cuestión que limitó su crecimiento y facilitó la acción de los grupos antifascistas y de los medios de comunicación de izquierda que exigían acciones gubernamentales en contra del PNF (Valdivia, 1995, pp. 6-10, 20). Sería esta estrecha identificación ideológica del PNF con el fascismo europeo, crecientemente desacreditado, una de las principales causas de su fracaso. A ojos de la opinión pública chilena de fines de los años treinta, suficientemente informada de la situación europea y de la violencia nazi, la defensa irrestricta que el PNF hacía de Berlín y Roma resultaba a todas luces negativo, aislándolo. Sin embargo, esta no es la única razón esgrimida por Valdivia para explicar el fracaso del partido de Olivares Maturana. A esta causa principal añade la neutralización del "peligro de subversión izquierdista" en el Chile de fines de década, que minó sus posibilidades de crecimiento sobre la base de una alianza con la derecha tradicional (Valdivia, 1995, p. 48).

Reconocemos el papel de Valdivia como precursora en el estudio de los grupos nacionalistas nacidos tras el quiebre del MNS y concordamos con ella en las razones detrás del fracaso del PNF: tanto el creciente descrédito internacional del fascismo, como la polarización de la política chilena de la época - con una derecha tradicional robusta, que no necesitaba del apoyo de una extrema derecha fascista- y la intransigencia ideológica del propio PNF condenaron a éste a una posición de marginalidad y al fracaso. No obstante, el trabajo de esta autora merece un par de observaciones. La primera, que los grupos estudiados por ella no son sólo nacionalistas, sino específicamente fascistas, como plantea Marcus Klein (2000), según veremos. La segunda, más importante desde el punto de vista de este trabajo, su inexplicable falta de interés por el antisemitismo del PNF -elemento ideológico fundamental del proyecto fascista de tercera vía abrazado por el partido de 
Olivares Maturana y fenómeno político-cultural ineludible a la hora de tratar el período histórico de Entreguerras.

Del mismo modo, creemos que de los trabajos de Marcus Klein (2000, 2001) sobre los fascismos del Cono Sur de los años treinta y cuarenta se desprenden importantes conclusiones con vistas a nuestro estudio. En primer lugar, Klein destaca el interés académico que se produjo en la década del noventa por el fascismo chileno de entreguerras, en particular por el MNS, aunque constata la existencia de un vacío académico respecto de los grupos nacidos tras su quiebre. La excepción a este vacío la constituye Verónica Valdivia y sus trabajos sobre las "nuevas voces del nacionalismo chileno", recién mencionados $(1993,1995)$. A diferencia de la historiadora chilena, Klein considera que esas "nuevas voces" no sólo fueron nacionalistas, sino específicamente fascistas. Ello porque el término "nacionalista" no connotaría una posición ideológica distintiva, considerando que durante los años treinta y cuarenta del siglo pasado distintos partidos asumieron posturas que pueden ser descritas como tales, poniendo como ejemplos los programas económicos propugnados por los partidos Socialista y Comunista. Por ello, la caracterización del PNF como "nacionalista" es insuficiente, pues soslaya su especificidad ideológica. Indudablemente el PNF - como antes el MNS- basó su discurso en el nacionalismo, pero desarrolló una "forma revolucionaria de ultra-nacionalismo" característica de los movimientos fascistas, pregonó la necesidad de un "renacimiento" que revirtiera la decadencia de la nación y le diera grandeza, así como el establecimiento de un nuevo orden totalitario que trascendiera el capitalismo liberal y el estatismo comunista y que uniera en su seno a todas las clases sociales organizadas jerárquicamente en una comunidad nacional. Todo lo anterior lleva a que Klein concluya que se trató en realidad de agrupaciones propiamente fascistas, y no simplemente nacionalistas, idea que compartimos plenamente (Klein, 2001, pp. 347-8).

En segundo lugar, Klein plantea que el PNF, como el resto de las agrupaciones surgidas tras el colapso del MNS - principalmente la Vanguardia Popular Socialista (VPS) y el Movimiento Nacionalista de Chile (MNCh) - fracasó en su intento por convertirse en un 
movimiento de masas tanto por factores internos como internacionales. Para Klein, las causas internas se encontrarían en la fuerza de la derecha tradicional y en la polarización del sistema político chileno, cuestiones que limitaron significativamente el espacio político en el que podía desenvolverse un partido como el PNF, impidiendo que encontrara su "nicho" propio, idea que compartimos plenamente; las razones internacionales, por su parte, habrían crecido en importancia a partir del estallido de la Segunda Guerra Mundial, haciendo que la pretensión del PNF de representar soluciones nacionales para los problemas de Chile perdiera credibilidad. Asimismo, las posiciones ideológicas defendidas por el fascismo se convirtieron a ojos de la opinión pública en radicales e impopulares. Por otro lado, el miedo a eventuales planes imperialistas del Tercer Reich en América Latina hizo que un grupo como el PNF, férreamente alineado con Alemania e Italia, fuera acusado permanentemente de formar la Quinta Columna del fascismo europeo en Chile. Vale decir, con el estallido de la guerra -y a medida que ésta se fue desarrollando- el fascismo perdió su prestigio como referente de solución a los problemas nacionales, condenando así, las aspiraciones de crecimiento del PNF (Klein, 2001, p. 349).

En tercer lugar, Klein destaca que mientras la VPS intentó hacerse de un espacio junto a la izquierda democrática, el PNF tomó la causa del fascismo en Chile e intentó ocupar el espacio dejado por el MNS en el espectro político. En este sentido, Klein cree que la razón que llevó al partido de Olivares Maturana a adoptar el nombre de Partido Nacional Fascista habría sido el deseo de enfatizar la naturaleza fascista del grupo y disipar así cualquier eventual desvío del fascismo europeo, como el experimentado por el MNS. En tal sentido, no cabe duda que el PNF quiso destacar desde un principio las diferencias con su antecesor, las que se reflejaron en su negativa a participar de procesos eleccionarios -salvo para apoyar la candidatura de Ross Santa María en contra de la de Aguirre Cerda- y en su “inflexible antisemitismo" (Klein, 2001, p. 354).

El desarrollo del fascismo chileno durante la presidencia de Aguirre Cerda, concluye Klein, se caracterizó por una declinación continua. A pesar de que el Frente Popular estaba en el poder, el PNF no fue capaz de capitalizar la existencia de un enemigo tangible y dar fuerza 
a su causa. Asimismo, la persistente fortaleza de la derecha tradicional y la polarización del sistema político limitaron el espacio político de las fuerzas de extrema derecha, minando de manera crucial su esfuerzo por hacerse de un nicho político propio. Los pactos electorales con la oposición conservadora - exitosos en atraer a sectores anticomunistas- ponen de manifiesto las dificultades que los grupos fascistas enfrentaron en este período. Además de los factores internos recién mencionados, Klein atribuye gran importancia al desarrollo de la esfera internacional para explicar el fracaso del PNF en convertirse en un movimiento de masas. Este aspecto está ligado, según él, al cambio de percepción respecto del fascismo a partir de septiembre de 1939. Desde entonces, el fascismo fue asociado con asesinatos masivos, campos de concentración y visto como una amenaza a la independencia y soberanía nacionales, condenando a grupos como el PNF (Klein, 2001, pp. 374-5).

Sin dudas, las conclusiones de Marcus Klein sobre el PNF suponen un importante aporte al estudio del fascismo chileno de los años treinta, sin embargo, nos parece que incurre en un error metodológico similar al de Valdivia: no someter el contenido de La Patria a un análisis formal. De haberlo hecho, se habría percatado de la utilización de material propagandístico antisemita -textos y caricaturas- de evidente origen europeo, que difícilmente pudieron llegar a manos de los editores de un semanario como La Patria sin algún grado de cooperación alemana, y de la colaboración del semanario fascista chileno con otras publicaciones antisemitas argentinas y uruguayas, como veremos a continuación.

\section{El antisemitismo del Partido Nacional Fascista de Chile (1938-1940)}

Pese a la centralidad ideológica que el antisemitismo tuvo para el PNF, Valdivia no le concede la importancia que merece ni lo somete a análisis en sus trabajos sobre el nacionalismo chileno de los años del Frente Popular (1993, 1995). Aunque destaca el vínculo que para los fascistas chilenos existía entre antisemitismo y anticomunismo, así como el rechazo a la inmigración judía, la autora no profundiza en estos temas, limitando el alcance de sus conclusiones. Y aunque su análisis del antisemitismo del PNF es más profundo que el de Valdivia, dándole una importancia más acorde a lo que las mismas 
fuentes sugieren, Klein $(2000,2001)$ tampoco aquilata completamente su importancia ideológica. Aunque reconoce que el inflexible antisemitismo del PNF marcaría una importante diferencia ideológica del partido de Olivares Maturana respecto del MNS, no profundiza mayormente en las características del antisemitismo del PNF, ni en cómo representaban a los judíos, ni en las consecuencias políticas y culturales de tales representaciones, ni en el origen del material propagandístico antisemita utilizado por $L a$ Patria, mucho menos en la respuesta de la colectividad judía chilena de la época frente a la campaña antisemita del PNF.

La ausencia del PNF y de su campaña antijudía en los reportes que la representación diplomática alemana en Chile enviaba a Berlín induce a Klein a menospreciar la importancia que el antisemitismo tuvo para el fascismo chileno de fines de los años treinta. ¿Qué habría motivado, entonces, a que el PNF desarrollara una campaña antisemita tan virulenta y sistemática? Cuando menos, ¿qué ayudaría a explicar tal decisión? Para el autor, en ello habría influido el creciente número de inmigrantes judíos llegados desde Europa a lo largo de los años treinta y el auge del antisemitismo en Europa, en especial desde que el régimen de Mussolini instauró política antijudías similares a las alemanas, en 1938. En esa línea, no sería de extrañar que la decisión de adoptar semejante discurso antijudío se hubiera basado en el deseo de subrayar la cercanía ideológica del PNF con la potencia fascista dominante, la Alemania nazi (Klein, 2001, pp. 356-8).

Respecto de una posible vinculación del PNF con los países del Eje, en particular con Alemania, y de un eventual financiamiento internacional, Klein afirma que no se han podido encontrar pruebas que lo confirmen (Klein, 2001, p. 358). Sin embargo, la publicación de un texto como el "Talmud (Schuljan Aruj)" en las páginas de La Patria, así como de otros textos y caricaturas antisemitas de evidente origen europeo, ponen en entredicho la seguridad con que Klein rechaza eventuales nexos entre el PNF y agentes nazis alemanes. En el mismo sentido, Klein soslaya la colaboración de La Patria con importantes publicaciones antisemitas argentinas -como Crisol y Clarinada- y uruguayas como Atención- (Guzmán Castro, 2012, pp. 143-55). 
Por último, Klein plantea que el radical antisemitismo del PNF habría colaborado significativamente en su fracaso. Según él, el partido de Olivares Maturana habría sido incapaz de trascender el pequeño círculo de ex nacistas fanáticamente antisemitas y de sobrellevar la carga que significaban su estrecha identificación con el Tercer Reich. Aunque en primera instancia el "virulento antisemitismo" del PNF logró atraer a ex miembros del MNS a sus filas, a la larga alejó a otros derechistas y nacionalistas con afinidades ideológicas al fascismo (Klein, 2001, p. 359).

Los resultados de nuestra investigación (Guzmán Castro, 2012) sugieren que el radical discurso antisemita contenido en las páginas de La Patria constituyó el elemento ideológico más importante del Partido Nacional Fascista. De manera mucho más sistemática y virulenta que las publicaciones nacistas, el semanario del PNF representó a los judíos como un colectivo de comerciantes ávidos e inescrupulosos, inventores y dominadores del capitalismo internacional, que no descansaría hasta conseguir el dominio mundial. Recurrentemente, los acusó de apropiarse de las riquezas chilenas, de la administración pública, de las profesiones liberales, de los tradicionales negocios del centro de Santiago, entre otras cosas. Asimismo, los acusó de inventar y dominar en su beneficio el comunismo, la masonería, el cine, la trata de blancas, y otros elementos propios de la modernidad. En tal sentido, no cabe duda que la influencia de los Protocolos de los Sabios de Sión fue mayor en el PNF que en el MNS y que la utilización política de esta "superstición política" fue más importante en el primero que en el segundo (Guzmán Castro, 2012, p. 164).

No obstante las similitudes entre los discursos antisemitas del MNS y el PNF, existen elementos de La Patria que lo distinguen de las publicaciones nacistas. Para el semanario fascista, los judíos no sólo eran prestamistas usureros y agitadores comunistas sino también narcotraficantes, estafadores y proxenetas que, con su acción, amenazaban la integridad de Chile. Por ello los consideró incompatibles con ocupaciones más nobles, como la agricultura y la milicia, llamando a su exclusión absoluta de ellas. Del mismo modo, La Patria se mostró más persistente que las publicaciones nacistasen su denuncia de una 
“invasión judía”, tal como vimos al comienzo de este artículo. Creemos que ello no es atribuible únicamente al considerable aumento de la inmigración judía al país a fines de los años treinta, como sugiere Klein, ni a los conflictos sociales que tal inmigración -como cualquier otra- pudiera suscitar, sino a opciones ideológicas específicas, tomadas del fascismo europeo. La Patria presentó permanentemente la llegada de judíos a Chile en términos de "amenaza" e "invasión", llegando al punto de afirmar que el país se estaba convirtiendo en "la Palestina de Sudamérica". En tal sentido, no es de extrañar sus incesantes alegatos en contra de la nacionalización de judíos y de su ingreso en la administración pública y las fuerzas armadas, dada la pretendida incompatibilidad entre judaísmo y chilenidad sostenida por el PNF. Según La Patria, la influencia judía en la sociedad chilena llegaba a tal punto que toda la política nacional se encontraba subordinada a los intereses del judaísmo, como supuestamente probaban la influencia de la empresa minera Hochschild y la instalación de la fábrica de zapatos Bata en la localidad de Peñaflor (Guzmán Castro, 2012, pp. 164-5).

Esta persistente campaña en contra de la inmigración judía hizo que el affaire de las coimas cobrara particular importancia para el PNF. Salido a la luz pública a fines de 1939, el escándalo por el pago de coimas para conseguir visados de ingreso a Chile favoreció un ambiente hostil a los inmigrantes judíos que se tradujo en el cese de esta inmigración a comienzos de 1940 (Nes-El, 2009). Sin embargo, el PNF fue incapaz de capitalizar dicho ambiente en su favor, encabezando el descontento generalizado en contra del rol de algunos judíos involucrados en el negociado y fortaleciendo su posición específica dentro de la derecha chilena. Ello pone de manifiesto el fracaso de la opción tomada por el PNF y de su intento por obtener un nicho propio sobre la base de un discurso antisemita radical, intransigente y similar al desarrollado por el nazismo alemán (Guzmán Castro, 2012, pp. 165-6).

En cualquier caso, existe una diferencia significativa entre los discursos antisemitas del MNS y el PNF que merece ser resaltada. Aunque La Patria no llegó a plantear que los judíos eran racialmente inferiores a los chilenos, sí afirmó que su rechazo a la inmigración 
judía se debía a una "cuestión de higiene y profilaxis", comparando su campaña antisemita con la acción de un médico que elimina las bacterias que amenazan la salud del cuerpo. Esta característica del antisemitismo del PNF no sólo debe ser vista como una cuestión formal, discursiva, pues tiene implicancias políticas más profundas. Tales afirmaciones, como muchas otras, alinearon al PNF con el nazismo alemán e intentaron movilizar a la opinión pública en contra de los judíos, culpándolos de la declaración de guerra británica en contra de Alemania y "limpiando" la imagen exterior del Tercer Reich. Aunque sin plantear una inferioridad racial judía respecto de los chilenos -cuestión que lo distingue del antisemitismo nazi alemán-, el PNF no dudó en referirse a los judíos que llegaban a Chile por esos días de "hez contagiosa", "gérmenes", "bacterias" y "parásitos", etcétera (Guzmán Castro, 2012, pp. 166-7).

Si bien Klein destaca que no se ha podido encontrar evidencia documental que compruebe de manera irrefutable la colaboración del PNF con los países del Eje, no cabe duda que las posiciones adoptadas por el partido de Olivares Maturana respecto de la cuestión judía aunque no sólo respecto de ella- se alinearon siempre con las seguidas por Alemania e Italia, recurriendo para ello a material propagandístico de origen extranjero. En tal sentido, debemos decir que nuestra investigación (Guzmán Castro, 2012) pone en evidencia la inclusión de material propagandístico de origen alemán en las páginas de La Patria, cuestión soslayada tanto por Valdivia $(1993,1995)$ como por Klein $(2000,2001)$. Como muestran las fuentes, el semanario fascista no sólo editó artículos provenientes de revistas antisemitas argentinas -Crisol y Clarinada- y uruguayas -Atención- sino también textos y material iconográfico de evidente origen nazi, que muy difícilmente pudieron haber llegado a manos de un pequeño partido de extrema derecha chilena sin la colaboración de agentes alemanes, como las secciones Talmud (Schuljan Aruj) y numerosas caricaturas. En tal sentido, creemos que el alineamiento del partido de Olivares Maturana con el Tercer Reich no sólo se debió a la admiración de los fascistas chilenos por el régimen de Hitler, sino que pudo ser consecuencia de intereses y apoyos más concretos (Guzmán Castro, 2012, p. 167). 
En vista de todo lo anterior, creemos que este antisemitismo secular de origen europeo adoptado por el PNF -distinto del antijudaísmo de origen cristiano- manifiestó todos los rasgos distintivos del antisemitismo moderno. En primer lugar, representó permanentemente a los judíos como una "organización comercial internacional" y un "complejo familiar mundial con intereses idénticos en todas partes" que, como "fuerza secreta tras el trono", era sospechosa de "conspirar para la destrucción de todas las estructuras sociales" (Arendt, 2004, pp. 62-72). De manera más persistente y radical que el MNS, el partido de Olivares Maturana vio en los judíos a un colectivo anacional incompatible con la nacionalidad chilena que pretendía conseguir ni más ni menos que la dominación planetaria por medio del capitalismo, el comunismo y un sinfín de invenciones ya descritas, siguiendo la lógica del "mito del judío" contenida en los Protocolos de los Sabios de Sión. En segundo lugar, nuevamente de una manera mucho más persistente y radical que sus antecesores nacistas, el PNF justificó y promovió la exclusión efectiva de los judíos de la sociedad chilena. Sin necesidad de recurrir a categorías de inspiración biológica, La Patria defendió la exclusión de los judíos de la sociedad debido a su "objetiva" nocividad, atestiguada por un sinfín de "pruebas". En palabras de Bauman, el PNF desarrolló una "estrategia de extrañamiento" en contra de la "categoría ofensora" representada por los judíos (Bauman, 1997, pp. 85-91). En tercer lugar, el antisemitismo del PNF intentó aprovechar aquel sentido común antijudío de la época -el "antisemitismo tradicional", en palabras de Gino Germani (1962)- para enunciar representaciones particularmente negativas respecto de los judíos, tomadas del repertorio antisemita europeo, y capitalizarlas políticamente en beneficio propio - “antisemitismo ideológico" diría Germani (1962)-. Apelando a este sentido común antijudío, el PNF intentó conseguir cierto grado de unanimidad social y política respecto de la supuesta nocividad judía, aunque sin éxito (Arendt, 2004, pp. 62-72). En cuarto lugar -y aquí radica el rasgo más importante del antisemitismo moderno de origen europeo desarrollado en Chile por el PNF-, este discurso fue utilizado no sólo para excluir a los judíos de la sociedad chilena, sino con otros fines políticos concretos, a saber, la construcción de un referente político fascista, el ataque al Estado liberal chileno y la defensa del Eje. Como señaló Arendt respecto del caso europeo, el antisemitismo del PNF no sólo se dirigió en contra de los judíos de carne y hueso, sino 
también contra el estado liberal y la democracia (Arendt, 2004, pp. 91-7) y, en el caso puntual de Chile, contra el Frente Popular y los partidos que lo formaban, a quienes acusó permanentemente de agrupación "judía” y "masona”, interesada en la destrucción de la chilenidad.

En síntesis, creemos que el antisemitismo del PNF intentó capitalizar un imaginario antijudío preexistente en el que los judíos ocupaban un lugar negativo, influido por el catolicismo y por la identificación de los judíos con el dinero, que en palabras de Germani (1962) cabría calificar como “antisemitismo tradicional”. Sobre la base de dichas tradiciones antijudías, el PNF desarrolló un sistemático y radical discurso antisemita de origen europeo, propiamente "ideológico", a través del cual no sólo atacó a los judíos mismos y a su inmigración a Chile sino también a sus adversarios políticos del Frente Popular, entonces en el gobierno, intentando así conseguir un espacio político e ideológico propio en la extrema derecha. Como sabemos, tal intento por construir una tercera vía fascista sobre la base del antisemitismo, así como la defensa del Eje, resultó un rotundo fracaso. En mayo de 1940, apenas dos años después del comienzo del "desbande nacista" cuando una porción importante de los militantes nacistas abandonaron el MNS acusando a González von Marées de traicionar la ideología fascista- que le había dado vida, el Partido Nacional Fascista de Chile desapareció por completo del escenario político chileno.

\section{Respuestas de la prensa antifascista chilena al antisemitismo del PNF (1938-1940)}

Como sintetizamos en otro lugar, la campaña antisemita desarrollada por el PNF suscitó la reacción explícita de la prensa judía de la época, principalmente del semanario sionista Mundo Judio, órgano que denunció en reiteradas oportunidades los intentos del partido de Raúl Olivares Maturana por instalar en Chile un antisemitismo de origen europeo e ironizó con la falta de originalidad de sus acusaciones (Guzmán Castro, 2014, 15-23). Las respuestas contra tales intentos, sin embargo, no provinieron únicamente de la colectividad judía sino también desde otros actores sociales, como el movimiento antifascista de fines de los años treinta. 
Dicho movimiento estaba conformado por una serie de agrupaciones. La primera de ellas fue la Liga de Defensa de la Cultura, nacida a fines de 1935 en repudio a la censura y la persecución de intelectuales emprendida por el gobierno alemán, las que se habían expresado recientemente en la quema pública de libros. Su declaración de principios publicada por el semanario sionista Mundo Judío- denunciaba "la exaltación guerrera y nacionalista" de los fascismos, exaltación que estaba "ejerciendo en el mundo una opresión de la inteligencia y un estancamiento de la vida espiritual", como se podía constatar "en la destrucción de libros, en la persecución racial y en la anulación de los derechos individuales" ocurridas en Alemania. "Si los intelectuales abandonaran las conquistas del espíritu, logradas por el esfuerzo y el dolor humano de siglos", proseguía la declaración, "la barbarie volvería a enseñorearse en el mundo" (Mundo Judío, 12 diciembre 1935, p. 3). Si bien esta agrupación no logró prolongarse mayormente en el tiempo, cabe destacar que entre sus fundadores se encontraban importantes escritores chilenos de la época como Augusto d'Halmar, Mariano Latorre, Marta Brunet y Manuel Rojas.

La segunda agrupación antifascista de importancia surgida durante los años treinta fue la Alianza de Intelectuales de Chile, fundada por Pablo Neruda a fines de 1937 con fines similares a los de la Liga de Defensa de la Cultura. Como ella, la Alianza de Intelectuales solidarizó con la situación de los judíos alemanes, destacando el masivo acto de repudio a la Kristallnacht que organizó en el teatro Caupolicán de Santiago el domingo 19 de noviembre de 1938. En dicho acto tomaron la palabra representantes de variadas organizaciones políticas y sociales, como el Partido Socialista (el diputado Julio Barrenechea), la Falange Conservadora (el diputado Ricardo Boizard) y el Movimiento Pro Emancipación de las Mujeres (la escritora Marta Vergara), además de intelectuales como Roberto Aldunate, Alejandro Lipschütz y el propio Pablo Neruda. Asimismo, expresaron su adhesión a la actividad la Confederación de Trabajadores de Chile, el Partido Comunista, el Pen-Club de Chile, la Federación Evangélica de Acción Social, agrupaciones de republicanos españoles y una agrupación médica de Valparaíso entre cuyos firmantes se encontraba el futuro Presidente Salvador Allende (Mundo Judío, 24 noviembre 1938, p. 1). Esta capacidad para movilizar a grupos sociales y políticos diversos en repudio al 
antisemitismo nazi, la participación en su seno de intelectuales de la talla de Neruda y Lipschütz, entre otros factores, sugieren que la Alianza de Intelectuales habría sido el grupo antifascista más importante del Chile de los años treinta. No obstante, dado que su acción no se centró en dar respuesta a los grupos fascistas y antisemitas chilenos como el PNF sino más bien en solidarizar con los judíos europeos, esta agrupación escapa al interés del presente artículo.

Pocas semanas después del acto organizado por la Alianza de Intelectuales en el teatro Caupolicán, y también como respuesta a la Kristallnacht, nació la agrupación antifascista más importante de los años treinta desde el punto de vista de este artículo: el Instituto AntiRacista de Chile. Como declarara su presidente y fundador, el senador radical Dr. Cristóbal Sáenz, esta agrupación había nacido en rechazo a "los crímenes cometidos por el Gobierno alemán en contra del pueblo judío" y como un medio de "defensa de la integridad de nuestra patria en contra de la penetración totalitaria", para lo cual resultaba necesario organizar "las huestes democráticas" chilenas contra el fascismo y prestar socorro a sus víctimas, por lo que hacía un llamado al gobierno del Presidente Aguirre Cerda a aceptar más inmigrantes judíos (Ercilla, 6 enero 1939, p. 11).

Desde luego, la fundación del Instituto Anti-Racista fue aplaudida por los editores de Mundo Judío, quienes celebraron que en la agrupación participara un amplio abanico de personas, "sin distinción de credos políticos ni religiosos", unidos únicamente por el rechazo irrestricto a "la teoría racista adoptada en los países totalitarios" y a las persecuciones antijudías llevadas a cabo por Alemania. El acta constitutiva del instituto destacaba el semanario sionista- llamaba a que el Estado de Chile siguiera "acogiendo benévolamente a todos los extranjeros, sin distinción de razas ni religiones, que deseen radicarse en su territorio y prosperar en él” (Mundo Judio, 29 diciembre 1938, p. 4).

Siguiendo el ejemplo de la agrupación encabezada por Sáenz, en enero de 1939 se formó el Comité Anti-Racista de Valparaíso (Mundo Judío, 19 enero 1939, p. 6) y en abril del mismo año la Asociación de Combatientes Antifascistas, integrada por republicanos 
españoles exiliados en Chile (El Frente Popular, 12 abril 1939, p. 12). No obstante la contribución de estos grupos al movimiento antifascista, desde el punto de vista de nuestra investigación la agrupación más importante fue el Instituto Anti-Racista de Chile, dado el rol que jugó en dar respuesta al antisemitismo del PNF y en movilizar a la opinión pública chilena no judía en su contra.

La voluntad de combatir a los grupos fascistas chilenos quedaría de manifiesto pocos días después de publicarse el primer número del semanario La Patria -junio de 1939-, cuando el Instituto Anti-Racista lanzó su propia publicación -quincenal- bajo el nombre de Civilización. Como era de esperar, Mundo Judío celebró la aparición de la publicación antifascista, pues "a la lucha que el antisemitismo ha emprendido por intermedio de una prensa creada especialmente para aquellos fines criminales, el Instituto respondió con la misma arma", creando "una tribuna de lucha, de combate" (Mundo Judío, 29 junio 1939, p. 3).

Aquel primer número de Civilización denunciaba que "todo el territorio nacional está siendo agitado por una ola de propaganda reaccionaria" que "obedeciendo a inconfesables intereses extranjeros pretende implantar en nuestra patria la exótica maleza de las luchas raciales". De este modo, "la opinión pública chilena ha visto con extraña sorpresa la aparición de la propaganda racista" de origen europeo, "cuyas finalidades tienden a la implantación de doctrinas absurdas, reñidas con la ciencia y con la dignidad humana", en referencia a La Patria. Esta publicación era, sin duda alguna, "el semanario fascista por excelencia, fundado para encender la lucha racista en el país, para convertir nuestra patria libre y generosa, en un trágico campo de concentración" (Civilización, 2a quincena junio 1939, pp. 1-2).

La declaración de principios del Instituto Anti-Racista -fundado formalmente en Santiago el 1 de diciembre de 1938- planteaba que su primer objetivo era conseguir que Chile siguiera "acogiendo benévolamente a todos los extranjeros, sin distinción de razas ni religiones, que deseen radicarse en su territorio y prosperar en él mediante el ejercicio de 
cualquier actividad honorable y socialmente útil", excluyendo a quienes intenten "constituir dentro de las fronteras del país minorías raciales o políticas, obedientes a inspiraciones de Gobiernos extranjeros", en alusión a los alemanes del sur de Chile. En segundo lugar, el Instituto declaraba su rechazo más enfático a "la teoría racista adoptada en los países totalitarios, según la cual la raza es un conjunto humano ligado principalmente por relaciones biológicas", y a los intentos que grupos como el PNF hacían por instalar dicha teoría en Chile. En tercer lugar, declaraba que "las persecuciones criminales y horrendas realizadas recientemente por los poderes nacistas alemanes en contra del pueblo judío (...) significan la negación de toda cultura, del derecho de gentes, y la regresión del hombre hacia el troglodita cavernario", comprometiéndose a "mitigar los daños ocasionados por el fascismo o el nazismo en cualquier parte del mundo y a evitar que se repitan persecuciones como las señaladas, atentatorias contra la civilización" (Civilización, $2^{\mathrm{a}}$ quincena junio 1939, p. 4). Sin duda, los lineamientos del Instituto Anti-Racista estaban perfectamente sintetizados en su lema: "Chile para todas las razas".

La solidaridad de Civilización con "los hombres del preclaro pueblo hebreo" quedó de manifiesto en varias oportunidades, como cuando, respondiendo a la acusación del PNF de que los judíos eran incompatibles con las labores agrícolas, destacó que desde "Besarabia, región húmeda de Rumania, han llegado campesinos judíos que tienen tras sí la experiencia de innumerables generaciones acostumbradas a las inclemencias del campo y no temen las lluvias sureñas que fertilizan el suelo de Valdivia hasta el Aysén”. En tal sentido, los editores de la publicación antifascista destacaban que quienes "afirman que el judío no es agricultor ignoran la colonización israelita en la República Argentina, creada hace medio siglo y que constituye un timbre de orgullo" para los judíos argentinos (Civilización, ${ }^{a}$ quincena julio 1939, p. 3).

Por cierto, el accionar del Instituto Anti-Racista no se limitó a la publicación de Civilización y a trabar polémica con La Patria. En julio de 1939, la agrupación del senador Sáenz anunció la realización de la "Primera Gran Jornada contra el Racismo y sus aliados el Nacismo y el Fascismo", en el teatro Caupolicán. Esta reunión de "todas las fuerzas de la 
cultura y de la democracia" tenía por objetivo "ilustrar a la opinión pública de Chile respecto a los graves problemas que amenazan a nuestra democracia y especialmente a combatir la penetración nazi-fascista en nuestro país" (Civilización, $2^{\text {a }}$ quincena julio 1939, p. 1).

La concentración se llevó a cabo de manera exitosa. Según Civilización, ello se debió al eficaz trabajo de propaganda desarrollado por el Instituto Anti-Racista, el que habría repartido volantes, organizado desfiles por las calles de Santiago, distribuido afiches y realizado una campaña radial para tal efecto. El positivo balance que el Instituto AntiRacista hacía de la jornada se debía, sobre todo, a que en ella se habían congregado "hombres y mujeres de todas las edades y de todas las condiciones sociales, sentados codo a codo", encontrándose allí a "el industrial, el comerciante, el profesional, el intelectual, el obrero, el estudiante", quienes podían pertenecer "a diversas razas, ideologías y religiones, pero hablan un solo lenguaje: la libertad" (2a quincena agosto 1939, p. 1). En la ceremonia tomaron la palabra representantes de variadas organizaciones sociales y políticas, como la Federación de Estudiantes de Chile, el Movimiento Pro Emanciación de las Mujeres, la Alianza de Intelectuales, la Juventud Nacional Chilena y el Partido Comunista, además del propio senador Sáenz (La Nación, 14 agosto 1939, p. 14).

Como era de esperar, durante los meses de septiembre y octubre la atención de Civilización se centró totalmente en la declaración de guerra de Gran Bretaña a Alemania, prácticamente desapareciendo de sus páginas las menciones al fascismo chileno. Recién en noviembre volvió a referirse a la "miserable pandilla de agentes de la reacción" liderada por Olivares Maturana, denunciando sus constantes ataques al Instituto Anti-Racista, agrupación a la que calificaban "de sinagoga judía, plagada de elementos marxistas y masones, apoyada financieramente por los elementos judíos". Ante ello, Civilización declaraba no ser "agencia de ninguna doctrina o institución determinada" y que "el elemento judío no financia ni ha financiado jamás nuestros actos"; los miembros del Instituto Anti-Racista no eran sino "hombres amantes de la Paz, de la Cultura y de la Democracia". Pero más importante que esta polémica con el PNF era el llamado que hacía Civilización a evitar la 
realización de la concentración fascista organizada por el partido de Olivares Maturana en el teatro Victoria, y que habría de llevarse a cabo la mañana del domingo 19 de noviembre: "Sería una traición a la democracia, a nuestras libertades públicas permitir que el insolente Partido Nacional Fascista se reúna al amparo de nuestras garantías constitucionales, para forjar el arma con que destruir nuestra propia existencia de República Libre y Democrática" (Civilización, $1^{\mathrm{a}}$ quincena noviembre 1939, pp. 1-2).

La concentración fascista del teatro Victoria también fue el tema central del editorial “iAlerta!”, donde se afirmaba que "las autoridades de la República deben poner fin de inmediato a la existencia de ese grupo de alienados mentales que, organizados en un partido Nacional Fascista, anuncian una concentración pública para el domingo 19 de este mes", pues el partido de Olivares Maturana intentaba "envenenar el alma de la juventud y de nuestro pueblo" y "destruir nuestra organización republicana y democrática, para servir intereses extranjeros o a círculos tenebrosos de la reacción chilena" (Civilización, ${ }^{\mathrm{a}}$ quincena noviembre 1939, p. 3).

Los deseos de los editores de Civilización se cumplirían pronto. La noche del miércoles 15 de noviembre, pocos días antes de la concentración fascista, un grupo de miembros del PNF asaltó las oficinas del Instituto Anti-Racista -ubicadas en calle Agustinas-y, al no poder forzar la puerta, robaron la placa de bronce y dejaron escrito en la pared "Mueran los judíos", hecho policial que fue cubierto por periódicos cercanos al gobierno del Frente Popular (La Hora, 17 noviembre 1939, p. 9; El Frente Popular, 17 noviembre 1939, p. 9;La Opinión, 20 noviembre 1939, p. 4). El ataque, que refrendaba las credenciales antidemocráticas y violentas del PNF, sumado a las sospechas de "Quinta Columna" que recaían sobre él, hicieron que el gobierno de Pedro Aguirre Cerda prohibiera la concentración del teatro Victoria y allanara los talleres donde se imprimía el semanario $L a$ Patria (El Frente Popular, 18 noviembre 1939, p. 6; La Crítica, 18 noviembre 1939, p. 1; ¡Qué Hubo!, 28 noviembre 1939, p. 2). 
A partir de entonces, la existencia del PNF se hizo cada vez más cuesta arriba: entre mediados de noviembre de 1939 y marzo de 1940, el partido de Olivares Maturana fue capaz de publicar únicamente cinco números -números que por primera vez repetían material antiguo-, tras lo cual desapareció de la escena política chilena. En junio de 1940, un año después del nacimiento de La Patria, el Partido Nacional Fascista de Chile se había esfumado.

\section{Conclusiones}

La campaña antisemita desarrollada por el PNF entre la aparición de su semanario La Patria, en junio de 1939, y su desaparición de la escena política chilena, a comienzos de 1940, fue mucho más agresiva, persistente y sistemática que la de su predecesor, el MNS, logrando importante notoriedad pública. Esta campaña, que intentaba instalar en Chile la "cuestión judía" y lavar la imagen exterior del Tercer Reich por medio de un novedoso discurso antisemita europeo, suscitó la reacción de la prensa judía, específicamente del semanario sionista Mundo Judio, y de la prensa antifascista, particularmente de la publicación quincenal Civilización, perteneciente al Instituto Anti-Racista de Chile. La respuesta de ésta última consistió en denunciar de manera sistemática el accionar del partido de Olivares Maturana, identificándolo como representante del fascismo internacional y enemigo irreductible de la democracia chilena e intentando movilizar a la opinión pública en su contra, y en solidarizar con los judíos europeos, pidiendo al gobierno del Presidente Aguirre Cerda aumentar la cuota de inmigración judía. En esta lucha contra el Partido Nacional Fascista de Chile y su campaña antisemita es reconocible, por cierto, un importante grado de colaboración entre la Federación Sionista de Chile, propietaria de Mundo Judio, y el Instituto Anti-Racista de Chile, publicando material conjunto -como la declaración de principios de éste último- y anunciando actividades de interés mutuo -como la concentración antifascista del teatro Caupolicán-. Desde luego, esta colaboración se debía a que ambos grupos tenían en el PNF un enemigo común. 
Se debe destacar también que el heterogéneo movimiento antifascista chileno de fines de los años treinta, que solidarizó con los inmigrantes judíos y llamó a movilizarse contra el fascismo, se nutrió principalmente de los grupos políticos cercanos a la izquierda y al gobierno del Frente Popular, como evidencia la lista de oradores de la concentración antifascista del teatro Caupolicán, la militancia política de sus miembros y la lista de medios escritos que exigieron e informaron con júbilo sobre la prohibición de la concentración fascista del teatro Victoria -La Opinión, El Frente Popular, La Hora-. Los principales medios de derecha -El Diario Ilustrado y El Mercurio-, en cambio, no hicieron mención alguna al accionar del Partido Nacional Fascista. Ni siquiera cuando atacó las oficinas del Instituto Anti-Racista o cuando organizó su fallida concentración del teatro Victoria.

Por último, lejos de potenciar el crecimiento del partido y de atraer nuevos militantes a sus filas, la campaña antisemita del PNF tuvo una importancia crucial en el fracaso de su proyecto político, dado el amplio rechazo que dicha campaña provocaba en la sociedad chilena, vastamente informada sobre los sucesos europeos, y la acción del creciente movimiento antifascista. 


\section{Bibliografía}

\section{Fuentes primarias}

Civilización, junio 1939 - junio 1940

Ercilla, mayo 1938 - junio 1940

El Frente Popular, mayo 1938 - junio 1940

La Hora, mayo 1938 - junio 1940

Mundo Judío, enero 1938 - diciembre 1940

La Nación, mayo 1938 - junio 1940

La Opinión, mayo 1938 - junio 1940

La Patria, junio 1939 - marzo 1940

\section{Fuentes secundarias}

Arendt, H. (2004). Los orígenes del totalitarismo. Primera parte: Antisemitismo. México: Taurus.

Bauman, Z. (1997). Modernidad y Holocausto. Madrid: Sequitur.

Bicheno, H. (1972). Anti-parliamentary Themes in Chilean History, 1920-1970. Government and Opposition, 7(3), 351-388. 
Cohn, N. (1983). El mito de la conspiración judía mundial. Los Protocolos de los Sabios de Sión. Madrid: Alianza.

Deutsch, S. M. (1996). Anti-Semitism and the Chilean Movimiento Nacional Socialista. En Sheinin, D. y Barr, L. B. (Eds.). The Jewish Diaspora in Latin America: New Studies on History and Literature (pp. 161-181). Nueva York: Garland.

Deutsch, S. M. (2005). Las derechas. La extrema derecha en la Argentina, el Brasil y Chile. 1890-1939. Buenos Aires: Universidad Nacional de Quilmes Editorial.

Etchepare, J. y Stewart, H. I. (1995). Nazism in Chile: A Particular Type of Fascism in South America. Journal of Contemporary History, 30 (4), 577-605.

Germani, G. (1962). Antisemitismo ideológico y antisemitismo tradicional. Criterio, 9, 5563.

Grugel, J. (1985). Nationalists Movements and Fascist Ideology in Chile. Bulletin of Latin American Research, 4 (2), 109-122.

Guzmán Castro, G. (2012). La patria sin judios: antisemitismo nacionalista en Chile, 19321940. Los casos del Movimiento Nacional Socialista y del Partido Nacional Fascista. Tesis de magíster, Universidad de Chile, 236 h.

Guzmán Castro, G. (2013). Al margen del antisemitismo: Respuestas del semanario Mundo Judío al Movimiento Nacional Socialista de Chile (1935-1938), Cuadernos Judaicos, 30, 51-69.

Guzmán Castro, G. (2014). Ironizando con el antisemitismo: Respuestas del semanario Mundo Judio al Partido Nacional Fascista de Chile (1938-1940), Cuadernos Judaicos, 31, 62-86. 
Klein, M. (2000). A Comparative Analysis of Fascist Movements in Argentina, Brazil and Chile between the Great Depression and the Second World War. Tesis doctoral, Universidad de Londres, Londres, Gran Bretaña.

Klein, M. (2001). The New Voices of Chilean Fascism and the Popular Front, 1932-1938. Journal of Latin American Studies, 33(2), 347-375.

Lvovich, D. (2003). Nacionalismo y antisemitismo en la Argentina. Buenos Aires: Vergara.

Nes-El, M. (2009). Los judíos y su actuación en la política chilena, 1920-1952. En Nes-El, M. Estudios sobre el judaísmo chileno (pp. 67-89). Jerusalén: Revista de Oriente y Occidente.

Pike, F. (1963). Chile and the United States, 1880-1962: The Emergence of Chile's Social Crisis and the Challenge to the United States Diplomacy. Notre Dame: University of Notre Dame Press.

Potashnik, M. (1974). Nacismo: National Socialism in Chile, 1932-1938. Tesis doctoral, Universidad de California, 365 h.

Ramírez Necochea, H. (1978). El fascismo en la evolución política de Chile hasta 1970. Araucaria de Chile, 1, 9-33.

Sznajder, M. (1990). El Movimiento Nacional Socialista: Nacismo a la chilena. Estudios Interdisciplinarios de América Latina y el Caribe, 1 (1), 41-57.

Sznajder, M. (1992). El nacionalsocialismo chileno de los años treinta. Mapocho, 32, 169193. 
Valdivia, V. (1993). Las nuevas voces del nacionalismo chileno, 1938-1942. Boletín de Historia y Geografía, 10, 119-139.

Valdivia, V. (1995). El nacionalismo chileno en los años del Frente Popular (1938-1952). Santiago: Universidad Católica Blas Cañas. 